\title{
The Modification of Sodium Polyacrylate Water Solution Cooling Properties by $\mathrm{AL}_{2} \mathrm{O}_{3}$
}

\author{
Wojciech Gęstwa and Małgorzata Przyłęcka \\ Faculty of Mechanical Engineering and Management, Institute of Materials Science and Engineering, Poznan University of Technology, \\ Pl. M. Skłodowskiej 5, 60-965 Poznań, Poland \\ Correspondence should be addressed to Wojciech Gȩstwa, wojciech.gestwa@put.poznan.pl
}

Received 19 January 2010; Revised 20 April 2010; Accepted 28 April 2010

Academic Editor: Luigi Nicolais

Copyright (๑) 2010 W. Gęstwa and M. Przyłęcka. This is an open access article distributed under the Creative Commons Attribution License, which permits unrestricted use, distribution, and reproduction in any medium, provided the original work is properly cited.

This paper presents a preliminary examination of water cooling ability as a result of its modification by the addition of sodium polyacrylate and $\mathrm{AL}_{2} \mathrm{O}_{3}$ nanoparticles. $\left(\mathrm{AL}_{2} \mathrm{O}_{3}\right)$ alumina oxide was present in gamma phase as a form of nanopowder whose particle size was less than $50 \mathrm{~nm}$. Cooling curves in the temperature-time system were marked for the three cooling media: water, $10 \%$ water solution of sodium polyacrylate, and $10 \%$ water solution of sodium polyacrylate with $1 \%$ addition of $\mathrm{AL}_{2} \mathrm{O}_{3}$ nanoparticles. Based on cooling curves, it can be concluded that for the water solution of sodium polyacrylate with $\mathrm{AL}_{2} \mathrm{O}_{3}$ nanoparticles in comparison to water and $10 \%$ polymer water solution lower cooling speed is obtained. The cooling medium containing nanoparticles provides lower cooling speed in the smallest surface austenite occurance (500-600 C) in the charts of the CTP for most nonalloy structural steels and low-alloy steels. However lower cooling temperature at the beginning of martensitic transformation causes the formation of smaller internal stresses, leading to smaller dimensional changes and hardening deformation. For the quenching media the wetting angle was appointed by the drop-shape method. These studies showed the best wettability of polymer water solution (sodium polyacrylate) with the addition of $\mathrm{AL}_{2} \mathrm{O}_{3}$ nanoparticles, whose wetting angle was about 65 degrees. Obtaining the smallest wetting angle for the medium containing nanoparticles suggests that the heat transfer to the cooling medium is larger. This allows slower cooling at the same time ensuring its homogeneity. The obtained values of wetting angle confirm the conclusions drawn on the basis of cooling curves and allowus to conclude that in the case of the heat transfer rate it will have a lower value than for water and $10 \%$ polymer water solution. In the research on hardened carburized steel samples $\mathrm{C} 10$ and $16 \mathrm{MnCr} 5$ surface hardness, impact strength and changes in the size of cracks in Navy C-ring sample are examined. On this basis of the obtained results it can be concluded that polymer water solution with nanoparticles allows to obtain a better impact strength at comparable hardness on the surface. Research on the dimensional changes on the basis of the sample of Navy C-ring also shows small dimensional changes for samples carburized and hardened in 10\% polymer water solution with the addition of nanoparticles $\mathrm{AL}_{2} \mathrm{O}_{3}$. Smaller dimensional changes were obtained for samples of steel $16 \mathrm{MnCr} 5$ thanfar C10. The results allowus to conclude that by the addition of solid nanoparticles to water based quenching media their cooling properties which are not inferior to mineral oils and polymer water solutions can be shaped.

\section{Introduction}

The hardening media with an addition of solid nanoscale particles which are the effect of modern nanotechnology create an opportunity to apply new processes and to producte materials with medium-sized crystallites of less than $50 \mathrm{~nm}$. Fluids with colloidal suspensions of nanoparticles are called nanofluids. This term was proposed by Choi of Argonne National Laboratory, USA in 1995 [1]. Nanofluids may be considered to be the new generation heat reception media offering new possibilities through the heat transfer enhancement in comparison to clean media (fluids). It can be expected that these media will have better properties than the conventional quenching media or the media containing microsized metallic particles. Increasing the actual surface of the nanoparticle contact point in comparison to conventional media should not only increase the heat transfer rate, but also raise the suspension stability. The beneficial 
properties of nanofluids allow the introduction of component miniaturization trend through the possibility to design smaller and lighter heat transfer systems [2].

The only work concerning quenching media modification by solid micro-or-nano-sized particles was published by Prabhu and Fernandes [3]. Its authors showed that through the suspension of nanoscale particles in water one obtains a quenching medium with a lower cooling speed, especially in the area of martensite transformation and the upper part of pearlite transformation in CTP diagrams.

It is also worth mentioning that it is not the only kind of nanoparticles which can be used in the quenching media. Other compounds or materials that can be used in the media, such as $\mathrm{CuO}, \mathrm{Cu}_{2} \mathrm{O}, \mathrm{Cu}, \mathrm{Au}$, and $\mathrm{Ag}$ are introduced in this work.

On the basis of these premises, this paper introduces the preliminary research on water cooling ability as the result of its modification by the addition of sodium polyacrylate and the $\mathrm{Al}_{2} \mathrm{O}_{3}$ nanoparticles.

\section{Research Methodology}

The quenching media in specified work parameters were investigated as shown in Table 1.

The evaluation of cooling intensity was conducted in compliance with the ASTM D D6200-97 standard; Standard Test Method for Determination of Cooling Characteristics of Quench Oils Cooling Curve Analysis (Tensi Method).

The test probe used in this method is cooled in the Tensi system. The tester applied in this probe has a diameter of $12.5 \mathrm{~mm}$ and is $60 \mathrm{~mm}$ long, it is made of INCONEL 600 alloy, with a Type $\mathrm{K}$ thermocouple inserted to the geometric center. The test probe was heated in a vertical resistance furnace that can assure the temperature of $850^{\circ} \mathrm{C} \pm 2.5^{\circ} \mathrm{C}$ at $120 \mathrm{~mm}$ in retort. The data obtained in the temperaturetime system is analyzed mathematically, as described in this paper, using the Fourier series [4].

In the investigation of the quenching media, the wetting angle of a quenching medium on a glass base was examined. The value of wetting angle measured by a goniometer is the measure of quenching mediums good wetting on a steel surface, it also allows comparing the quenching media on a glass surface. The wetting angles were appointed by the drop-shape method. The Tracker device of I.T. Concept was used for this purpose. The optical system of this device is composed of a CCD camera with a $640 \times 512$ pixel resolution and lenses which record light shedding at a right angle. The investigated sample of a liquid drop on a solid surface stands in the way of radiation. The measurement is based on the analysis of a drop shape of a known volume which most often equals $2 \mu \mathrm{L}$. The drop is ejected automatically from a syringe by a capillary on a solid surface. The drop shape recorded by the optical system is analyzed by Win Drop software on the basis of Laplace-Young equation. The investigation of the wetting angle was conducted in the Institute of Technology and Chemical Engineering, Division of Chemical Engineering at Poznan University of Technology.
Ordinary steel 10 (according to ISO C10) and chromiummanganese steel $16 \mathrm{HG}$ (according to ISO:16MnCr5) were used for the investigation purpose. Chemical composition of the investigated steel grades was compliant with their chemical composition presented by the PN-EN 10083:2008 and the PN-EN 10084:2008 standards. The C10 and 16MnCr5 steel grades were applied by dint of their structure in the initial state. The C10 steel in the initial state, has a ferriticpearlitic structure, which allowed us to obtain the structure of supersaturated ferrite or the mixture of ferrite and pearlite in the core after the application of diffusion and hardening processes. The $16 \mathrm{MnCr} 5$ steel on the other hand, in the initial state, has a pearlite-ferrite structure, which allowed, to obtain the structure of martensite with retained austenite or bainite structure in the core. All this led to acknowledgement of the core structure influence on the obtained properties of the carburized elements.

Following mechanical processing, the investigated samples underwent a normalizing annealing process. The processing temperature was adjusted to each grade of steel individually and did not exceed the range of austenite state occurrence in the steel, that is, $30-50^{\circ} \mathrm{C}$ over the Ac3 line (in compliance with the Table 2).

Cooling to ambient temperature was conducted in calm air (cooling speed lower than critical). This process made it possible to obtain a fine and homogeneous actual grain in samples prior to the realization of the next thermal-chemical and thermal processes.

The carburization process was carried out at $925-930^{\circ} \mathrm{C}$ for 7 hours. Endothermic atmosphere (propane-butaneair) with unstable carbon potential $(1,24 \% \mathrm{C}$ and $0,8 \% \mathrm{C})$ was applied in the carburization process. The researched processes were conducted at the $\mathrm{H}$. Cegielski-Poznań S. A. Company, where annealing furnace EFCO-ROYCE, CTtype equipped with a carbon potential controlling oxygen probe as well as in a computer controlled system SCR7000 with exactitude of $\pm 0.01 \%$, was used. To minimize the soot production and to achieve optimal carbon diffusion, the carbon potential was maintained with the help of a dynamic computer control system. To ensure an even and homogeneous flow of the carburizing atmosphere round the samples during the carburization process, the samples were hung on separate handles of an instrument placed in the furnace.

After carburization, the samples were subjected to a single-hardening process. This method of hardening eliminates the production of coarse acicular martensite, which affects the obtaining lower of and heterogeneous properties of the carburized elements. The austenitization temperature was adjusted to the investigated steel grades using the collected data concerning its characteristic temperatures. The temperature was correspondingly $830-860^{\circ} \mathrm{C}$. The austenitization time was 0,5 hours. Using various quenching media of definite work parameters was an essential part of the hardening process. During processing, the samples were protected from oxygenation and decarburization.

The examination of the hardened carburized elements' surface and section hardness was carried out using the Vickers method with $0,1 \mathrm{~kg}$ load, in compliance with PN-EN 
TABLE 1: Investigated quenching media.

\begin{tabular}{lcc}
\hline Quenching medium & Work temperature $\mathrm{Tp}\left[{ }^{\circ} \mathrm{C}\right]$ & Agitation $\mathrm{Vc}[\mathrm{m} / \mathrm{s}]$ \\
\hline Distilled water & 20 & 0 \\
$10 \%$ polymer water solution & 20 & 0 \\
$10 \%$ polymer water solution $+1 \%$ of $\mathrm{Al}_{2} \mathrm{O}_{3}$ nanoparticles & 20 & 0 \\
\hline
\end{tabular}

TABLE 2: The parameters of normalization.

\begin{tabular}{lccc}
\hline Grade of steel & Recommended processing temperature $\left[{ }^{\circ} \mathrm{C}\right]$ & Annealing temperature $\left[{ }^{\circ} \mathrm{C}\right]$ & Processing time $[\mathrm{h}]$ \\
\hline $\mathrm{C} 10$ & $900-930$ & 910 & 0,5 \\
$16 \mathrm{MnCr} 5$ & $860-900$ & 890 & 0,5 \\
\hline
\end{tabular}

ISO 6507-1:2007, with the Zwick hardness tester, as well as using the Rockwell method, scale $\mathrm{C}$ in compliance with PNEN ISO 6508-1:2007 (PN/H-04355). Five samples for each grade were produced.

According to PN/H-04253 the thickness of the hardened layer is measured as the distance between the surface $(\times 550 \mathrm{HV})$ and the $550 \mathrm{HV}$ hardness spot (HV550 hardness criterion). The impact strength measurement was carried out on $55 \times 10 \times 5$ u-notch impact strength samples using the Charpy method in compliance with PN-EN 10045-1.

\section{The Results}

The mathematically analyzed data concerning the cooling abilities of individual quenching media, obtained as the result of an experiment, are presented in temperaturetime and temperature-cooling time systems as depicted in Figure 1.

The realized investigations were conducted in accordance with the method to determine cooling ability of quenching media, which used the probe with Inconel 600 alloy. The detailed description of this method was introduced in research methodology of this paper. The changes of temperature in the probe center do not fully characterize the quenching medium in research, especially for large elements, where the difference in speed of warmth receipt between surface and core occurs. However, the results obtained by this method allow comparing quenching media in this research to each other as well as to different quenching media offered by manufacturers who present data obtained by this method in their informative cards about quenching media.

The obtained cooling curves allow us to reach a conclusion that the introduction of polymer in a waterbased quenching medium allows lowering of the speed of heat transfer from the heated element. Adding $\mathrm{Al}_{2} \mathrm{O}_{3}$ nanoparticles boosts the effect. In the time-temperature system significantly lower cooling speed below the temperature of $800^{\circ} \mathrm{C}$ and stabilization of cooling way below the temperature of $100^{\circ} \mathrm{C}$ can be observed. A more complete view of the cooling speed changes in each quenching medium is presented by the data in the temperature-cooling speed system (Figure 1(b)). It shows that the $10 \%$ water solution of sodium polyacrylate and the $10 \%$ water solution of sodium polyacrylate with $\mathrm{Al}_{2} \mathrm{O}_{3}$ nanoparticles have the lowest cooling speed. The difference between these two media is also shown by the maximum cooling speed value and the temperature at which it occurs (chart3) with an advantage for the $10 \%$ water solution of sodium polyacrylate with $\mathrm{Al}_{2} \mathrm{O}_{3}$ nanoparticles. The maximum cooling speed for this quenching medium covers the temperature range of the lowest austenite occurrence area on CTP diagrams for the majority of constructional steel grades.

The values of cooling speed presented in Table 3 at 700, 500 , and $330^{\circ} \mathrm{C}$ and the previously mentioned maximum cooling speed led to a conclusion that the most beneficial system was obtained for the $10 \%$ water solution of sodium polyacrylate with $\mathrm{Al}_{2} \mathrm{O}_{3}$ nanoparticles. It confirms previous conclusions reached in the case of cooling curves in the temperature-time and temperature-cooling speed systems.

The wetting angle for these quenching media was appointed by the drop-shape method on a glass surface with the use of Tracker device of I.T. Concept for this purpose.

The investigation revealed the best wetting (Figure 2) for the $10 \%$ water solution of sodium polyacrylate with $\mathrm{Al}_{2} \mathrm{O}_{3}$ nanoparticles, the wetting angle of which was around $65^{\circ}$. $10 \%$ polymer water solution had the highest wetting angle value of $77^{\circ}$. The wetting angle for distilled water reached the level of $72^{\circ}$. Reaching the lowest wetting angle by the $10 \%$ polymer water solution with $1 \%$ of nanoparticles suggests that the heat reception surface of this quenching medium is larger.

It can be confirmed on this basis that the quenching medium with the addition of nanoparticles ensures quicker cooling in the range of the lowest austenite occurrence area on CTP diagrams for this steel grade and slower cooling in the range of initial martensitic transformation temperature, which ensures lower stress values, lower dimension changes, and less deformation of the hardened elements.

The obtained impact strength values of each carburized steel grade presented in Figure 3 differed significantly depending on the used quenching medium. High impact strength values regardless of the steel grade were obtained for the samples hardened in $10 \%$ sodium polyacrylate with $1 \%$ of $\mathrm{Al}_{2} \mathrm{O}_{3}$ nanoparticles. It is the result of less stress occurring in the samples which were cooled at a lower speed in a quenching medium with nanoparticles.

The obtained larger impact strength for the samples hardened in $10 \%$ sodium polyacrylate with $1 \%$ of $\mathrm{Al}_{2} \mathrm{O}_{3}$ nanoparticles can be explained by changes of cooling speed in this medium. The cooling medium with the addition 


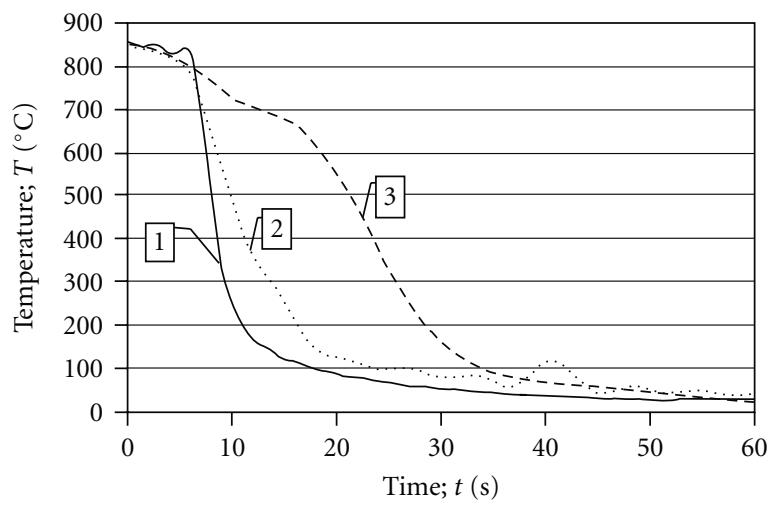

(a)

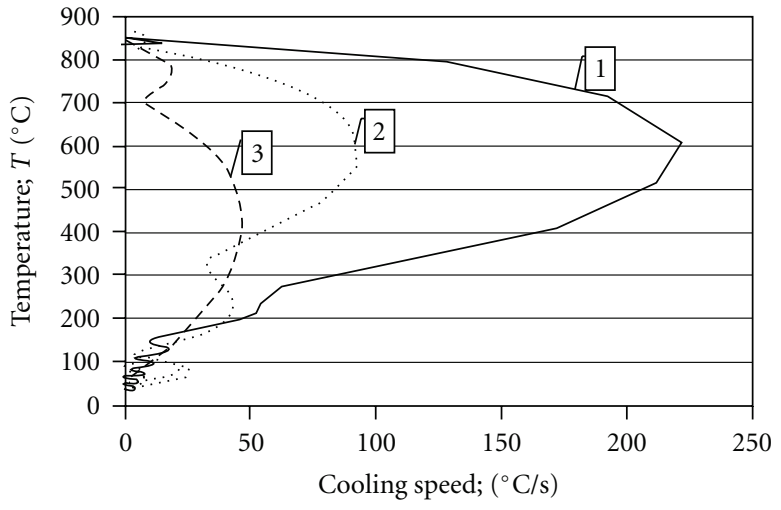

(b)

FIGURE 1: The cooling curve after mathematical analysis based on Fourier series for distilled water (1), 10\% polymer water solution with (3) and without (2) $1 \%$ of $\mathrm{Al}_{2} \mathrm{O}_{3}$ nanomolecules in co-ordinate systems: (a) Time-Temperature; (b) Cooling speed-Temperature.

TABLe 3: Characteristic cooling speed values.

\begin{tabular}{|c|c|c|c|c|c|}
\hline Quenching medium & V700 [ $\left.{ }^{\circ} \mathrm{C} / \mathrm{s}\right]$ & V550 [ $\left.{ }^{\circ} \mathrm{C} / \mathrm{s}\right]$ & $\mathrm{V} 330\left[{ }^{\circ} \mathrm{C} / \mathrm{s}\right]$ & $\mathrm{Vmax}\left[{ }^{\circ} \mathrm{C} / \mathrm{s}\right]$ & $\operatorname{Tmax}\left[{ }^{\circ} \mathrm{C}\right]$ \\
\hline Distilled water & 535 & 525 & 180 & 664 & 563 \\
\hline $10 \%$ water solution of sodium polyacrylate & 60 & 50 & 90 & 98 & 643 \\
\hline $10 \%$ water solution of sodium polyacrylate with $\mathrm{Al}_{2} \mathrm{O}_{3}$ nanoparticles & 23 & 90 & 60 & 111 & 408 \\
\hline
\end{tabular}

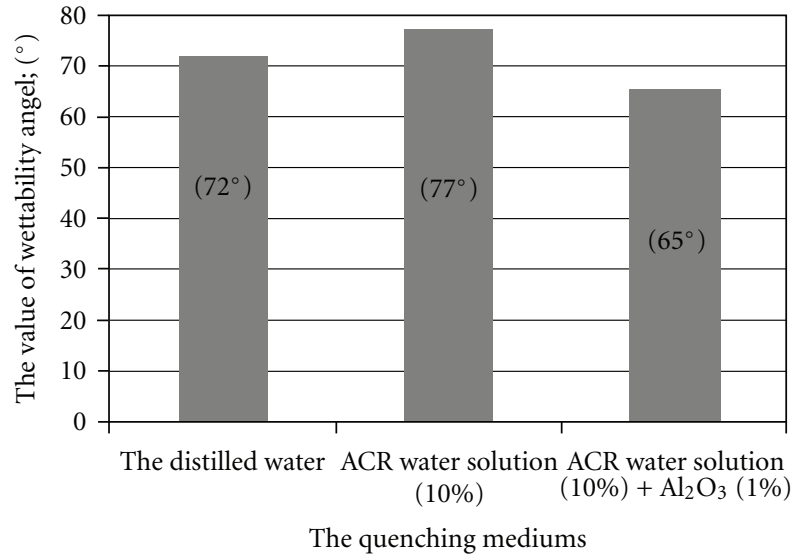

FIgURE 2: The value of wetting angle for water-based quenching media.

of nanoparticles assures quick cooling in the range of the smallest area of occurrence of austenite $\left(500-600^{\circ} \mathrm{C}\right)$ on TTT diagram for these steels. This allows us to avoid the occurrence of ferrite and pearlite in hardened structures. Slower cooling temperature at the beginning of martensite transformation assures formation of smaller residualal stresses. In final effect this gives smaller dimension changes and smaller deformation of hardened elements. This is connected with smaller tetragonality of martensite formed in structure of these steels.

The obtained surface hardness values of the investigated carburized $\mathrm{C} 10$ and $16 \mathrm{MnCr} 5$ steel samples showed comparable values in the range of $60-65 \mathrm{HRc}$ regardless of the used quenching medium. It is caused by the carbon content

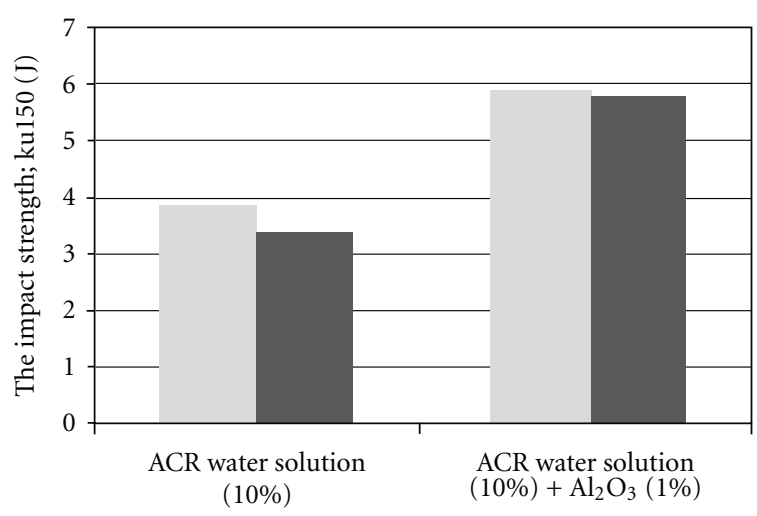

The quenching mediums

The impact strength (ku150)-C10 steel

The impact strength (ku150)-16MnCr5 steel

FIgURE 3: The influence of quenching media on impact strength of hardened and carburized C10 and 16MnCr5 steel samples'.

$(0,8 \% \mathrm{C})$ on the samples' surface, which ensures that the cooling speed obtained in the investigated quenching media is higher than the critical speed for each steel grade. The carbon content on the surface of the investigated samples allows obtaining a martensitic structure of a comparable hardness for each steel grade. Higher hardness values were obtained for the $16 \mathrm{MnCr} 5$ steel, owing to its better hardenability.

Figure 4 presents the results of dimensional change of a Navy C-ring sample investigation. The results showed little dimensional changes for the samples carburized and hardened in $10 \%$ polymer water solution with $1 \%$ of $\mathrm{Al}_{2} \mathrm{O}_{3}$ 


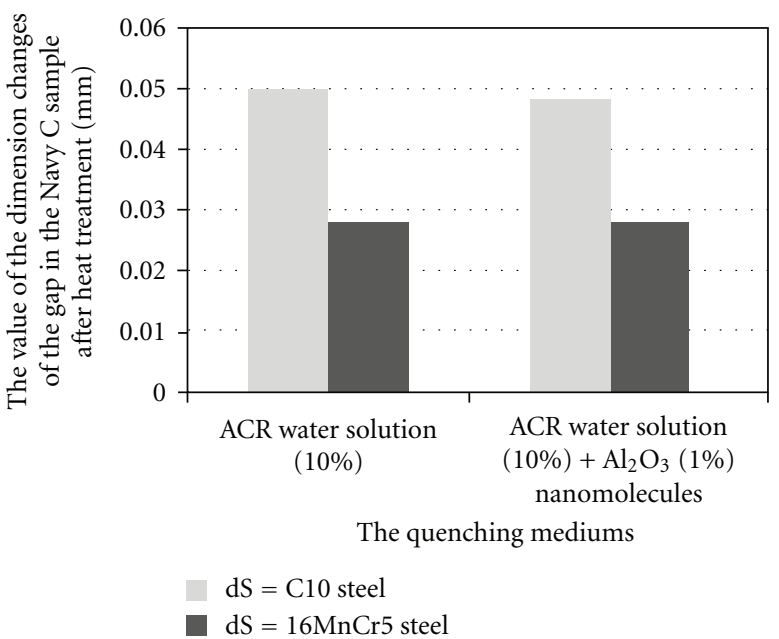

FIGURE 4: The influence of quenching media on dimension changes of a Navy C-ring sample made of hardened and carburized C10 and $16 \mathrm{MnCr} 5$ steel.

nanoparticles. However, these changes were on the same level with the changes observed for the samples carburized and hardened in $10 \%$ sodium polyacrylate, regardless of the steel used for the samples. Nevertheless, the obtained values of dimensional changes were lower for $16 \mathrm{MnCr} 5$ steel than they were for the C10.

On the basis of the obtained results, it can be stated that the use of polymer water solution with $\mathrm{Al}_{2} \mathrm{O}_{3}$ nanoparticles led to achieving higher impact strength (Figure 3 ) together with a comparable surface hardness and dimension changes (Figure 4) for the samples made of $16 \mathrm{MnCr} 5$ and $\mathrm{C} 10$ steel. The results of the investigations allow us to reach a conclusion that by the addition of the nanoscale particles of a solid body to the quenching media, their cooling abilities may be shaped.

From the economic point of view the utilization of solid body nanoparticles in quenching media can cause growth of price of such cooling centre. However, this price can be amortized by the obtained improvement of the property of material quenched in it as well as the lack of modernization of hardening devices for its use.

\section{Conclusions}

In the course of the conducted research, the following was concluded.

(i) Modifying the quenching media by the suspension of $\mathrm{Al}_{2} \mathrm{O}_{3}$ nanoparticles results in better cooling abilities compared with the traditionally used cooling media.

(ii) The cooling curves and their characteristic points show that the cooling process is slowest in the quenching media with nanoscale particles.

(iii) The quenching media with nanoscale particles have a lower thermal conductivity, which was confirmed by the maximum value of the heat transfer coefficient and its occurrence at lower cooling temperatures. (iv) These quenching media also appear to have a smaller glass wetting angle in comparison to other investigated cooling media.

(v) Hardening in the media with nanoscale particle suspensions allows us to obtain higher impact strength in comparison to the impact strength of the samples hardened in the media without added nanoparticles for both the $\mathrm{C} 10$ and the $16 \mathrm{MnCr} 5$ carburized steel samples.

(vi) Higher surface hardness was obtained on carburized and hardened $16 \mathrm{MnCr} 5$ steel samples than that obtained for the C10. No significant influence of the quenching media on the surface hardness value was observed.

(vii) When it comes to the dimension changes, lower values were obtained for the carburized $16 \mathrm{MnCr} 5$ steel, however, regardless of the steel grade, the lowest values of the dimension changes were obtained for the samples hardened and carburized in $10 \%$ polymer water solution with $1 \%$ of $\mathrm{Al}_{2} \mathrm{O}_{3}$ nanoscale particles.

(viii) Suspending $\mathrm{Al}_{2} \mathrm{O}_{3}$ nanoscale particles in the quenching media can shape their cooling properties. Such media with nanoparticles tend to display more beneficial properties compared with the polymer water solution quenching media.

\section{References}

[1] S. U. S. Choi, "Enhancing thermal conductivity of fluids with nanoparticles," in Developments and Applications of NonNewtonian Flows, FED-vol. 231/MD-vol. 66, pp. 99-105, 1995.

[2] P. Keblinski, J. A. Eastman, and D. G. Cahill, "Nanofluids for thermal transport," Materials Today, vol. 8, no. 6, pp. 36-44, 2005.

[3] K. N. Prabhu and P. Fernades, "Nanoquenchants for industrial heat treatment," Journal of Materials Engineering and Performance, vol. 17, no. 1, pp. 101-103, 2008.

[4] I. Felde, T. Reti, and X. L. Chen, "Efficient data encoding and filtering for quenching analysis," in Proceedings of 3th International Conference On Quenching And Control Of Distortion, pp. 208-215, ASM, Praga ,Canal zone, USA, March 1999. 

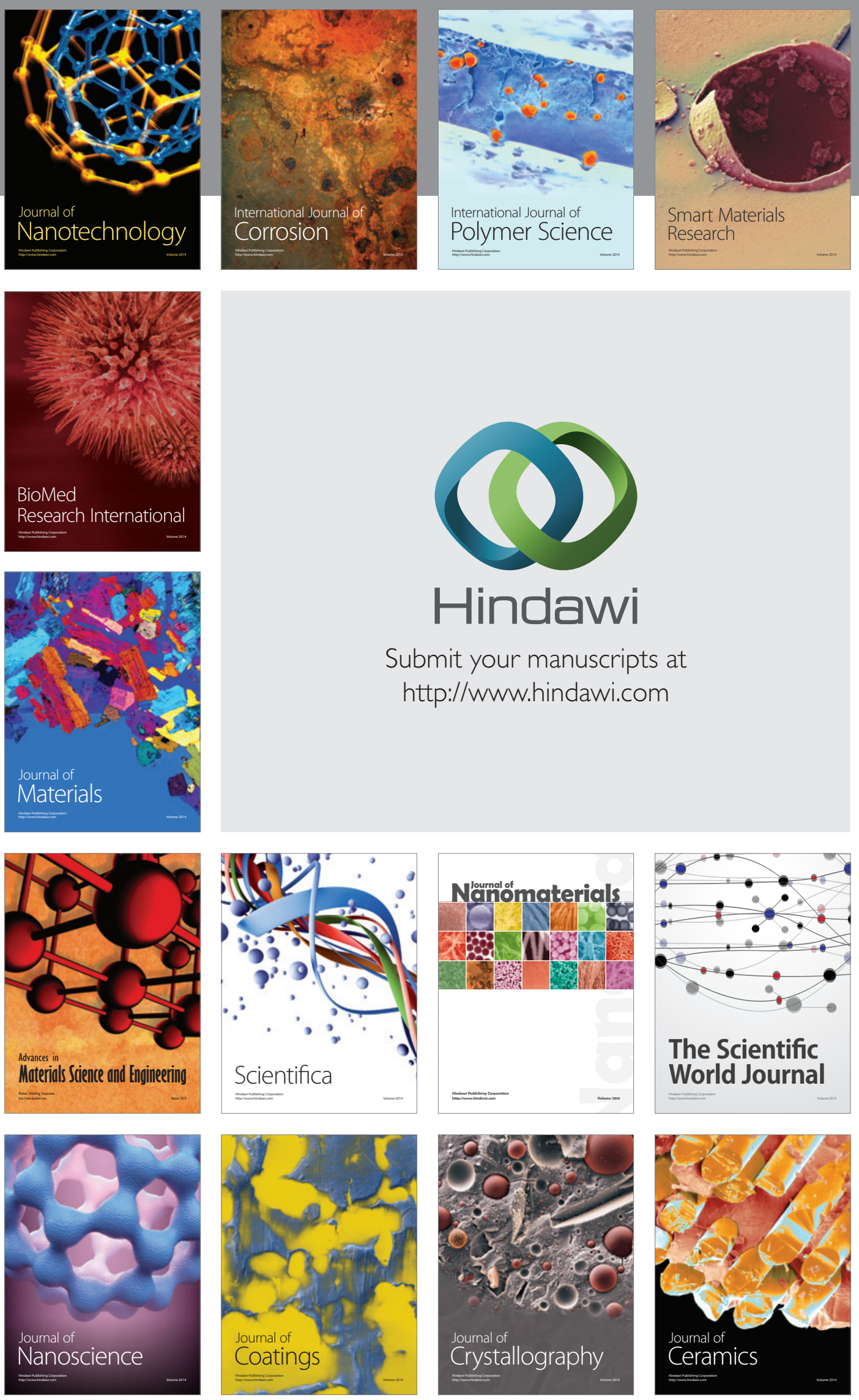

The Scientific World Journal

Submit your manuscripts at

http://www.hindawi.com

\section{World Journal}

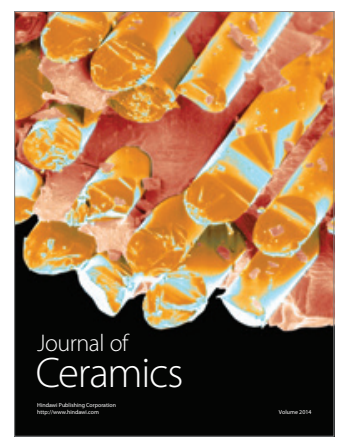

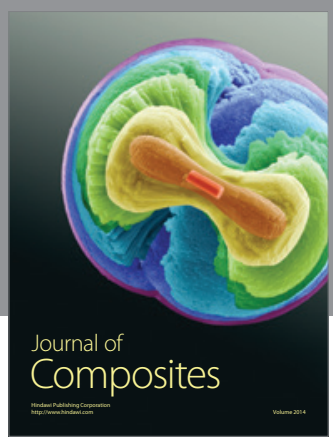
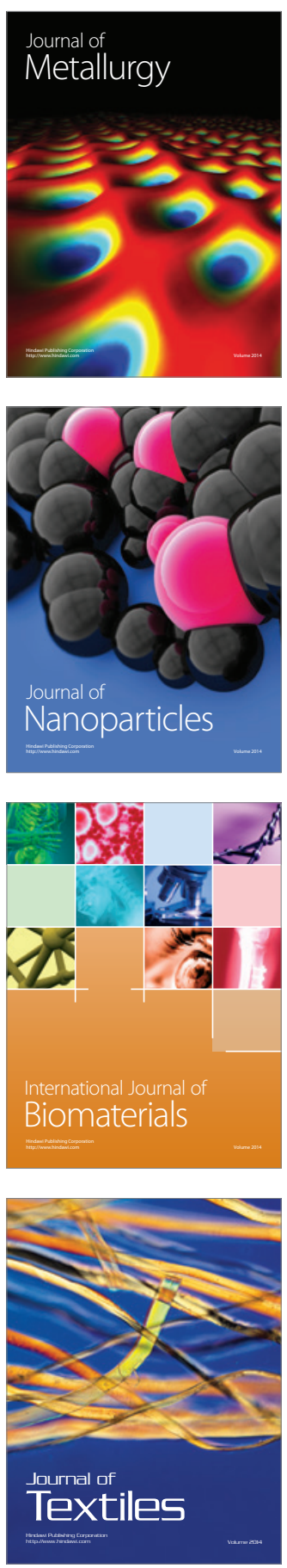